\title{
MOTOR VEHICLE SAFETY REGULATION: GENESIS
}

\author{
CrawFord Morris *
}

On September 9, I966, President Johnson signed into law the National Traffic and Motor Vehicle Safety Act of $1966 .^{1}$ For the first time in its history, the largest single industry in the United States, comprising the producers of on-highway motor vehicles, was to be regulated. The account that follows covers the struggle over formulation of the first regulations under this law. ${ }^{2}$ The resolution of that struggle was eventually a compromise, reached in a cooperative atmosphere that has worked so well it is hoped that it will be a precedent for all future regulation in this field. The experience has been instructive for all concerned, and some effort is made at the end of this article to generalize from it. The use of the administrative process to devise answers to complex scientific and technological questions is an art that has not yet been mastered, but it is possible that the case history here recounted will contribute to the development of institutions that will meet this challenge.

\section{I}

\section{ETrology}

Once some sort of federal regulation became an inevitability, industry ${ }^{3}$ moved forward, even in advance of the legislation, in an attempt to work out meaningful, workable regulations with government in discussion meetings. These attempts proved futile until after the showdown of the "trial by evidence" herein reviewed, which finally produced the meaningful communication necessary for the formulation of workable regulations. Part of the problem may have lain with government, somewhat suspicious of being overwhelmed by industry, part with industry, not used to being regulated, part with the extreme political overtones of the entire affair, part with the acute time pressures imposed by unrealistic statutory deadlines, part with the magnitude and complexity of the task, and part with the need for

* Member of the Ohio bar and of the law firm of Arter, Hadden, Wykoff \& Van Duzcr, Clevelancl, Ohio. Special counsel to the Automobile Manufacturers Ass'n, Inc., in the field of "bio-mechanies" in the proceedings on the petitions for reconsideration of Initial Standard 20r, discussed herein.

In the interests of readability minor liberties have occasionally been taken with the extensive quotations included in this article. Thus, omissions are not always indicated where sense does not require it, stenographic crrors (in records, etc.) have been corrected, and paragraphing and punctuation have occasionally been altered.

180 Stat. 7I8. [Hereinafter, unless otherwise noted, citations to the National Traffic and Motor Vehicle Safety Act will be by section number only.]

${ }^{3}$ The formal proceeding described herein is officially designated In the Matter of Initial Federal Motor Vehicle Safety Standards, Dkt. No. FHA-I (Federal Highway Administration, 1967). For brevity, it is hereinafter referred to as "FHA-r."

${ }^{3}$ Twenty-seven automobile manufacturers and importers participated in the reconsideration of Standard 201. In addition, the Automobile Manufacturers Association, Inc. represented the four of its eleven members who produce passenger cars, each of which also appeared for itself. 
bringing into being a new agency to administer the task. To understand this "trial. by evidence" one must have some appreciation of the preceding events, which will be briefly recorded here chronologically.

August 24, I966. The Automobile Manufacturers Association, Inc. (AMA) formed a Safety Standards Committee to assist in formulating industry's views as to the content and effective date of the standards to be developed and to submit these views to government authorities administering the then proposed act. Becaúse of the short time remaining before the proposed January $3^{\mathrm{r}}$, I967, deadline for issuing initial standards, the AMA instructed the committee to begin work immediately so that the government could be provided at the earliest possible date with the necessary basic data and technical information. The committee was to review all existing safety standards, including those of the General Services Administration (GSA) controlling purchase of cars by the government, the Interstate Commerce: Commission, and the Society of Automotive Engineers. From these it would prepare proposed standards, which were to be submitted to the government for consideration as initial standards. This approach reflected the anticipated statutory directive that the initial standards be based on existing safety standards.

September 8, 1966. The AMA sent a letter to the Secretary of Commerce. requesting informal meetings to explore the problem together. This letter pledged "full cooperation ... in the implementation of the legislation" and suggested "that an early meeting might well be in order to discuss effective ways of carrying out that cooperation."

September 9, 1966. The National Traffic and Motor Vehicle Safety Act of 1966 was signed into law by President Johnson. Those portions of the act of interest here provide for regulation of the auto industry by requiring the Secretary of Commerce (his authority was later shifted to the Department of Transportation) to issue safety standards which must be met in every motor vehicle manufactured after the effective date of the regulation. In so providing, Congress wrote into the law measures to protect the economy by requiring the Secretary to give due consideration in establishing standards to such factors as leadtime, economic and technological feasibility, and consumer demand. These limitations were especially important with regard to the initial standards here discussed because so little time remained between the projected issuance date (January 3r, 1967 ) and the 1968 models to be affected thereby, for which production was to begin in August 1967 and for which initial planning had commenced as much as thirty-six or more months earlier. The limitations on the Secretary's authority are reflected in the statutory provisions requiring that the standards be (I) "reasonable, practicable and appropriate," (2) "mini-

\footnotetext{
Letter from Roy Abernethy, Chairman of the AMA, to Secretary of Commerce John T. Connor, Sept. $8,1966$.

${ }^{5} \mathrm{f}_{\mathrm{ro}}(\mathrm{f})$. See S. Rep. No. 130r, 8gth Cong., 2d Sess. 6 (1966) [hereinafter cited as S. REP. Ño. I30I]; H.R. Rep. No. 1776, 89th Cong, $2 \mathrm{~d}$ Sess. I6 (I966) [hereinafter cited as H.R. REp. No. r776].
} 
mum," (3) "able to meet the need for motor vehicle safety," (4) performance standards, not design standards, ${ }^{8}$ (5) "objective," and (6) "based upon existing safety standards." 10 The act further provided that the Administrative Procedure Act was to apply to all orders establishing, amending, or revoking safety standards. ${ }^{13}$

September 14, 1966. The meeting which industry had requested was held at the Department of Commerce. In the course of that meeting, Undersecretary Boyd (subsequently the Secretary of Transportation) emphasized the necessity for dialogue between government and industry, remarking that a long-range program was being begun; that its success would depend on developing mutual respect and trust and on avoidance of public recriminations; and that, while some disagreement was inevitable, criticism should always be on a professional basis.

October 17,2966 . The AMA submitted to the government a detailed series of proposed initial motor vehicle safety performance standards, covering nineteen items, prepared by the AMA's Safety Standards Committee. Each of the proposals consisted of three basic parts-a brief description of the proposal followed by the proposed standard itself and a technical critique.

November $x$, 1966. The AMA submitted ten additional proposals covering passenger cars and approximately 125 proposals for trucks, buses, and special-purpose vehicles.

In all, these proposals covered 3105 pages of technical comments and data. Nevertheless, industry felt that the standards were too complicated to be dealt with solely on the basis of extensive written submissions and requested that informal discussions also be held. In its November I submission, the AMA also said,

The proposals submitted herewith, together with those we submitted on October I7, cover the substance of the existing Federal safety standards referenced in your notice published on October $8, x 966 . \ldots$

We have proposed a number of new standards applicable to other aspects of vehicle safety not now covered by Federal standards. . . . In a number of cases we have proposed modifications of existing standards-particularly the GSA procurement standards-because these existing standards do not meet the statutory requirements of performance criteria stated in objective terms, or because leadtime, engineering, manufacturing, procurement, or cost versus benefit considerations make it impracticable in our judgment to meet a particular requirement in all 1968 model vehicles.

As in the case of the 19 proposals submitted on October 17 , some of the enclosed proposals are more design oriented than a literal reading of the statute might permit. We have offered such proposals in recognition of the possibility that, in cases where adequate performance data are still lacking, you may prefer to

\footnotetext{
${ }^{\circ} \$$ ro2. See S. REP. No. 1301, at 5; H.R. REP. No. I776, at 16

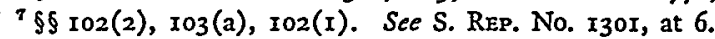

\$ IO2(2). See S. Rep. No. I30I, at 6.

- \$ $102(a), 103(a)$. See H.R. Rep. No. 1776 , at $x 6$.

.${ }^{10} \S$ I03 $_{2}(\mathrm{~h})$. See S. REP. No. I30I, at 5-6.

11 ro3(b). See H.R. Rep. No. $x 776$, at 16 ; S. Rep. No. 1301 , at $7,8$.
} 
issue some standard rather than none as a temporary policy improvisation. In such cases, we reserve our right to object to any new and revised standards that are not supported by adequate data and do not meet all the requirements of the Act.

As you will appreciate, our detailed proposals for standards have been prepared under extreme time pressure. Upon further review, it may be necessary for us to amend our suggestions in some technical respects, or to propose exceptions or special requirements for various vehicle types. . . .

It is interesting to observe that had government accepted these proposals as written, it would have achieved initial standards of greater severity and covering more aspects of performance than those it finally adopted. Conversely, industry would have had to comply with stricter initial standards, some of which ${ }^{12}$ industry, on further study, found in need of substantial revision.

Notwithstanding industry's request for informal discussions, the agency felt compelled, due to the time pressures involved and the lack of staff, to proceed without such discussions.

November 30, 1966. The government issued its Notice of Proposed Rule Making ${ }^{13}$ setting forth twenty-three proposed standards and giving industry until January 3 , I967, to submit detailed comments.

January 3, 1967. Industry submitted detailed comments to each of the twentythree proposed standards. The comments of the AMA on the standard which is the focus of this article, Standard No. 20r-Occupant Protection in Interior Impactincluded the following:

[T]his proposed standard presents very serious compliance problems for the automobile industry. It is the position of the [AMA] that the requirements ... concerning the "unrestrained child impact area," maximum pressure upon impact, "projections," and armrests are not based on existing standards and are, therefore, not within the statutory power of the Secretary of Commerce to issue as initial safety standards. These unprecedented requirements, together with others enumerated and discussed below, are also unreasonable and impracticable, particularly for incorporation in I 968 model year passenger cars.

Many of the requirements of this proposed standard, particularly those, relating to projections, are expressed in design terms, rather than in performance terms as required by the Act. We recognize that this is necessary to some extent for an initial standard ... because of the present lack of data for forming a true performance standard. However, the proposed design constraints go beyond existing standards and there is no warrant under the Act for imposing them, particularly in the absence of data showing a correlation between them and improved safety, and the inability of manufacturers to comply with them for 1968 model vehicles.

The objectives of this proposed standard are obviously of great importance and further improvements in performance values that can reasonably be prescribed for 1968 model vehicles should be further considered for adoption in a new

${ }^{22}$ E.g., armrests. See p. 542 infra.

${ }^{10} 3$ I Fed. Reg. 15600 (1966). 
revised standard. Meanwhile-apart from the paragraph relating to sun visors, to which AMA does not object, and the provisions relating to armrests, for which AMA has suggested an addition-we believe that the new requirements, the lack of supporting data, the ambiguities and the uncertainties posed by the other provisions of this proposed standard need study and resolution before they are incorporated in a standard. Accordingly, we submit that they should be deferred pending consideration of new and revised standards.

Again, industry requested meetings to work out the technical difficulties involved: "Through such a meeting . . . the Secretary . . . would have an opportunity to hear further from the manufacturers with respect to the proposed initial standards, or revision thereof."

January 25, 1967. The government granted only one such meeting, which was held on this date. The statutory deadline of January $3^{\mathrm{I}}$ was too close and the meeting proved too general in nature to permit resolution of the problems inherent in the twenty-three proposed initial standards. At this meeting, Dr. William Haddon, Director. of the National Traffic Safety Agency (NTSA), the body immediately responsible for standard setting within the Commerce Department, remarked on the time schedule on which the Agency was forced to operate as the result of the law's September 9 enactment and the lack of operating funds until November 16. To industry he said, "So if you think you have leadtime problems, you should consider some of ours. At least we have a basis for sympathy for the problems that you have been faced with." Dr. Haddon indicated that the January $3 \mathbf{1}$ deadline would be met but that the specifics of the standards could not be constructively discussed at the meeting because of their still unfinished state. However, he endorsed the principle of informal contacts with industry as a means for working out specifics in the future but noted that deficiencies in the Agency's staff precluded at that time the more extensive dialogue that all concerned appeared to desire.

Agency leaders may also have felt the political pressures were such that they could not accede to industry's request for further negotiations of reasonable standards, and that the proposed standards as issued would have to be tested publicly.

fanuary 3I, 1967. Government issued its initial safety standards, twenty in number. ${ }^{14}$ The standards were in most respects quite similar to the GSA standards on which they were based. ${ }^{15}$

By and large, industry did not question the twenty initial standards. A number had been specifically modified to meet industry comments (a matter which resulted in public criticism as noted hereafter), and it was generally believed they could be "lived with." The principal exception was Initial Standard 20r, which industry felt presented problems too critical to let pass. Even here, however, industry had no desire for a showdown with the Agency but hoped that the Agency would either

\footnotetext{
14 32 Fed. Reg. 2408 ( 1967 ). Three of the originally proposed standards were not finalized but werc made the subject of an Advance Notice of Proposed Rule Making. 32 Fed. Reg. 2417 (1967).

${ }^{15}$ For the full text of GSA's amended Federal Standard No. 515, see 3I Fed. Reg. 9628-38 (1966).
} 
accept the changes previously suggested by industry or have discussions with industry about them. Only after it was apparent that this would not happen, and when time was running out, did industry file its petitions for reconsideration.

Standard 20I was different in degree from the other standards, for it raised most sharply the fundamental question of the extent of industry's duty to produce a product that would provide some protection when misused by the consumer for a purpose never intended, namely crashing it into another object. In Evans $v$. General Motors Corp., ${ }^{16}$ a divided court of appeals had held that there was no such duty, saying,

The intended purpose of an automobile does not include its participation in collisions with other objects, despite the manufacturer's ability to foresee the possibility that such collisions may occur. As defendant argues, the defendant also knows that its automobiles may be driven into bodies of water, but it is not suggested that defendant has a duty to equip them with pontoons.

Subsequently, however, in Larsen $v$. General Motors Corp., ${ }^{17}$ another court of appeals took a different view, saying,

We do agree that under the present state of the art an automobile manufacturer is under no duty to design an accident-proof or fool-proof vehicle or even one that floats on water, but such manufacturer is under a duty to use reasonable care in the design of its vehicle to avoid subjecting the user to an unreasonable risk of injury in the event of a collision. Collisions with or without fault of the user are clearly foreseeable by the manufacturer and are statistically inevitable.

....

We perceive of no sound reason, either in logic or experience, nor any command in precedent, why the manufacturer should not be held to a reasonable duty of care in the design of its vehicle consonant with the state of the art to minimize the effect of accidents.

The ultimate issue was the scope of the tort principle of foreseeability-that is, does the fact that a certain number of motor vehicle accidents are so inevitable as to be foreseeable by industry place upon industry the concomitant duty to so design the product as to reduce the consequences of such misuse of the product by the consumer? In entering this field, the agency was pioneering new ground legally as well as in engineering. Industry did not question the legal power of the agency to do this, and indeed the agency seems clearly to have power to act in the field, since the statute defines motor vehicle safety to include protection of the public "against unreasonable risk of death or injury to persons in the event accidents do occur."18 But while industry agreed that the objectives sought were important, it quarreled with the engineering feasibility of the specific requirements of 201 and with its failure to meet the statutory requirements for initial standards.

\footnotetext{
${ }^{10} 359$ F.2d 822, 825 (7th Cir. 1966), cert. denied, 385 U.S. 836 (1966).

${ }^{17} 39$ I F.2d 495, 502, 503 (8th Cir. I968).

${ }^{18} \mathrm{IOZ}_{\mathrm{O}}(\mathrm{I})$.
} 
From an engineering viewpoint, the question was one of a functional systems approach versus 20r's generalized "pingpong ball inside the car" approach. The trauma to occupants from the so-called "second collision" was a virgin field virtually unknown to engineering and bio-mechanics in $1966-67$, but the new agency entered it at breakneck speed primarily because of the time pressure of political events. It is no wonder that industry felt compelled to take a stand here.

March 6, 1967. Industry filed its petitions for reconsideration of Initial Standard 20r. Attached to the AMA's petition was a detailed mark-up of 201 showing the changes which were believed necessary to make it "reasonable, practicable and appropriate" and otherwise in accordance with the statutory requirements. The reasons for the proposed changes were discussed in detail. Interestingly enough, just as with the AMA's proposals of October 17 and November 1 , if the Agency had accepted the changes proposed by the AMA at this time, Standard 201 would have been more stringent than the final version which eventually emerged and would have posed serious compliance problems in some instances. The reason for this was, of course, the pressure of time and the complexity of the matter. Like the Agency, industry was writing about unknown problems and engineering facts as the engineers themselves were testing for more knowledge. Indicative of the confusion and time pressures under which both industry and government were working in a complex engineering field was the AMA's discussion of armrests in its petition. After proposing specific amendments, the AMA concluded, "We recognize that some of the language in Initial Standard 20I to which we now take issuc was suggested by AMA in its earlier comments, but further study of this matter has persuaded manufacturers that the amendments now proposed are necessary."

When it subsequently became clear that the issues would not be resolved within the statutory period provided for judicial review, some manufacturers, as a protective measure, filed review petitions with the U.S. Court of Appeals for the Sixth Circuit. As it turned out, the matter was resolved without pursuing this remedy.

With the issuance of the initial standards, internal dissension broke out within the NTSA, culminating in the resignation of the Agency's chief technological adviser, Mr. Stieglitz. Stieglitz was an advocate of issuing only strict permanent standards, with postponement of the effective date if necessary to accommodate for leadtime and other problems, whereas Dr. Haddon favored initial standards to meet the effective date of the statutory mandate even if they had to be watered down to allow for industry compliance. Stieglitz's position was better engineering, but Haddon's was better politics-and the problem had vast political overtones.

March 20 and 2i, 1967. Hearings on the initial standards were held before the Senate Committee on Commerce. ${ }^{10}$ At these hearings Stieglitz stated that, in his opinion, "what should have been done on many of these standards was not to

\footnotetext{
${ }^{10}$ Hearings on Implementation of the National Traffic and Motor Vehicle Safety Act Before the Senate Comm. on Commerce, goth Cong., Ist Sess. (1967)..
} 
weaken the safety requirements or achievement, but to change the effective date to provide [for] a legitimate leadtime requirement of industry." He further stated that "some of [his] proposed standards could not possibly have been met for Ig68 automobiles," but that his preference for stronger standards was based on a feeling "that things had to start moving forward, and this leadtime block had to be broken."20 Mr. Ralph Nader also criticized the Agency's initial standards:

Finally, the Agency's decision to issue a number of totally inadequate standards for r 968 instead of issuing meaningful ones and deferring part or all of their application date where absolutely necessary gives industry grounds to object to sound advances in forthcoming standards on the basis that they represent too great an expansion from the I968 model levels and too little leadtime-a kind of neverending merry-go-round from one year to the next. Industry representatives will be able to point to the evaluation of the 1968 standards by the Agency whose Administrator, instead of attaching to them the requisite modesty they deserved, called them, among other praise, a great step forward. ${ }^{21}$

At the hearings, Undersecretary of Commerce Bridwell (subsequently to become Federal Highway Administrator) answered "an unequivocal no" when asked if the auto industry had placed "any pressures on you to weaken standards, other than through 'on the record' submission of statements and conferences."22 Dr. Haddon testified at length concerning the Agency's problems in meeting the short deadline established by Congress. He stated his differences with Mr. Stieglitz as follows:

I think the primary problem here was one in which he advocated a course of action for those parts of standards which could not be accomplished for the r 968 models and had to be deferred, in that he wanted to go ahead and issue the standard or the portion of the standard on January 31 for application in 1969 or 1970 models, as the case might be.

The choice, or the option before us, was whether to do that or whether to proceed, as it ultimately turned out we did, to try to seek more definitive information, more data, more research, before tackling the other portions of the standard. ${ }^{23}$

Following these hearings, which contain much criticism of the Agency's standards -criticism that received a good deal of attention in the press-the Agency evidently felt that it had gone as far as it could politically in modifying the initial standards. Fearing increased criticism if it yielded to further modification, the Agency "froze" and insisted upon a public hearing on industry's petitions, notwithstanding industry's continued pleas for informal negotiations. While this hearing probably best served the public interest (as we hope to show below), it might have been better for industry's relations with the Agency and for the over-all public interest in the

\footnotetext{
${ }^{20} I d$. at 158 .

${ }^{21}$ Id. at 209 .

${ }^{22} I d$. at 104 .

${ }^{23}$ Id. at 114 .
} 
advancement of motor vehicle safety if this legal confrontation, with its adversary bitterness, could have been avoided.

April $x$, 1967. The National Traffic Safety Agency became the National Highway Safety Bureau (hereinafter the "Bureau") and was transferred to the Department of Transportation on the creation of that new cabinet department. ${ }^{24}$

\section{ENGINEERING}

As reflected in the Senate hearings of March 20-21, 1967 , the engineering details of the standards are too complex for facile comprehension by the uninitiated, or even by law-trained senators used to tackling complex problems. Accordingly, in this article, which addresses itself to the administrative aspect of motor vehicle safety regulation, the engineering side is largely ignored. However, since these administrative aspects were, of necessity, based upon and largely controlled by the engineering details involved, it is best now to reduce the general to the specific in a few illustrative instances and to give the reader some engineering background from which to judge the administrative maneuverings and rulings on Standard $20 r$.

Standard 20r was assertedly based, as it was required by statute to be, upon existing standards, in this case six GSA standards which dealt with the subject of interior occupant protection. ${ }^{25}$ Beginning in August 1966, the AMA's Safety Standards Committee rewrote these six GSA standards to incorporate the changes believed necessary to express them in the objective performance terms required by the statute and to make them appropriate for the entire broad range of passenger cars instead of the limited types of vehicles purchased by the government, to which the GSA standards applied. In October and November 1966, the AMA submitted these six rewritten standards to the Agency as proposals for standards. Each proposal was accompanied by a summary and a detailed critique explaining the changes, and each contained the original text of the GSA standard together with all proposed language changes.

The Agency's proposed Standard 20I, issued on November 30, 1966, largely ignored the AMA proposals and other industry suggestions. It also departed in a number of respects from the GSA standards. Apart from having one rather than six separate standards, the differences from the GSA standards included the following important matters:

(a) Requirements were added which were not in the GSA standard-requirements for protection of the unrestrained child and requirements for a maximum pressure of pounds per square inch in areas of contact.

\footnotetext{
${ }^{24}$ See 31 Fed. Reg. ${ }_{5212}$ (I966), corrected 3I Fed. Reg. 15600 (1966). Mr. Lowell K. Bridwell, Acting Undersecretary of Commerce for Transportation, became Federal Highway Administrator, rcsponsible for administering the safety act.

2x $\$ 103(h)$. See note 15 sitpra.
} 
(b) The definitions of impact areas and related terms which had been an integral part of each GSA standard were separately stated and materially changed.

(c) GSA dealt with projections by specific categories, as is apparent from the titles of the GSA standards-e.g., instrument panel instruments and control devices, window and door controls, etc. The proposal dealt with "projections" on an all-inclusive basis. The term was not defined, but was broadly stated to include "knobs, switches, levers, handles, bezels, and panel contours." These in turn were also undefined.

In addition, the proposal specified a deceleration requirement of $80 \mathrm{~g}$ for I millisecond $(80 \mathrm{~g} / \mathrm{rms})$ although industry had stated that $80 \mathrm{~g} / 3 \mathrm{~ms}$ was the most that could be accomplished for all ig68 models.

The industry comments filed on January 3,1967 , urged changes throughout proposed Standard 20r and the related definitions, with the sole exception of the provisions relating to sun visors. The AMA comments on the "unrestrained child impact area," set forth in part here, suggest the nature of the differences between the AMA and the government:

AMA recognizes that the unrestrained child in a passenger car is a problem that deserves the full attention of the automobile industry and of the Government. However, the most direct and practicable approach to the problem appears to be the development of adequate child restraint systems, together with education of the public to use them. The requirements concerning the so-called "unrestrained child impact areas" . . . should be deleted from the initial standard because they are ambiguous, because they are based on no existing standard, because they are inconsistent with other requirements of the proposed standards, and because they are impracticable.

$\cdots$

Even if there were a legal basis for the Secretary's "unrestrained child impact area" proposals, redesign or retooling of automobile interiors to shield from impact or soften all surfaces or controls in the areas that can be reached by unrestrained children would be impracticable for r 968 model passenger cars and probably for several years thereafter.

The AMA also objected to "the absence, in the Secretary's proposal, of the GSA provision permitting flat, broad armrests designed to overlap the pelvic region."

On January 3I, I967, the Agency issued its Initial Standards. Some changes were made in Standard 20I as issued to meet industry comments. Thus, the unrestrained child and maximum contact pressure requirements were dropped, and the armrest provision was amended and a definition of pelvic impact area was added. In other respects, the industry's suggestions were passed over. ${ }^{26}$ The other impact area definitions remained unchanged. The term projections was changed to protrusions but otherwise continued to be treated on an undifferentiated and undefined basis, although the requirements which they had to meet were rewritten

\footnotetext{
${ }^{20}$ See 32 Fed. Reg. at $241_{3}$ (x967).
} 
and expressed as alternatives. The deceleration requirement was left at $80 \mathrm{~g} / \mathrm{rms}$, and the test procedures were not clarified as industry had requested.

The industry petitions for reconsideration reiterated the unsatisfied previous objections and covered additional points raised by the changes made in 201 as issued; they were supported by additional information not available at the time of the January 3 comments. The AMA petition, in particular, suggested changes in the definitions of "head impact area," "knee and leg impact area," "pelvic impact area," "H point," and "95th percentile adult male," and changes in the provisions of the standard dealing with deceleration requirements, test procedures, protrusions, and armrests. A complete rewrite of 201 and its related definitions was submitted as part of the petition. The only portion of the standard unchanged was the provision relating to sun visors.

After the evidentiary hearing on the petitions for reconsideration, it was perfectly clear that the Agency, operating under the pressure of time and lack of staff, had indeed assembled definitions and requirements so poorly thought out as to be completely unworkable. The principal problems lay first in definitions which were so ambiguous as to lead to multiple interpretations and, however interpreted, to be unworkable in many instances. Second, the Standard did not specify test procedures with sufficient clarity to measure performance to ascertain compliance or noncompliance; different interpretations of the test procedures were possible which might, and probably would, yield different performance results. Third, the Standard in certain instances did not utilize known test devices (such as the so-called "lollipop" for delineating the head impact area) but instead called for the use of devices not even in existence (a ninety-fifth percentile adult male manikin and a fifth percentile adult female manikin). Fourth, some of its requirements (such as those for protrusions) were so generalized as to apply indiscriminately to hundreds of different items and areas rather than to specify precise performance requirements for particular items and areas. The brief recitation of the evidence below will help to illustrate the depth and seriousness of some of these problems. ${ }^{27}$

III

\section{The Proceedings}

\section{A. Procedure}

The opening gambit came from industry in a move that was partly substantive but partly procedural, designed to contain the proceedings within the protection of formal evidentiary rules by which compliance with the statutory safeguards could be adequately determined. ${ }^{28}$ In its petition for reconsideration, the AMA stated,

Thus far the Secretary has chosen to conduct these proceedings under the informal rule-making procedures of Section 4 of the Administrative Procedure Act

${ }^{27}$ See notes 30-32 infra.

${ }^{28}$ How well this succeeded is shown by the excerpt from the Bureau's brief set forth at pp. $554-55$ infra. 
[5 U.S.C. $\$ 553(1964)$ ]. This choice was understandable in view of the statutory requirement that the Initial Standards be issued by January 31, I967, and up to this point it has worked well. The Congress made clear, however, that whether to utilize the informal rule-making procedures of Section 4 of the Administrative Procedure Act or the more formal procedures of Sections 7 and 8 of that Act [5 U.S.C. $\$ \$ 556,557(1964)$ ] depended on the circumstances of the situation. And even when proceedings are conducted under Section 4 of the Administrative Procedure Act, the procedures to be followed must be "more elaborate" when matters of great importance are involved.

Now that twenty Initial Standards have been issued, only one of which has given rise to petitions for reconsideration involving major legal and factual issues, it seems both necessary and appropriate to invoke more "elaborate" and painstaking procedures, whether under Section 4 or Sections 7 and 8 of the Administrative Procedure Act, to the extent necessary for a full factual and legal exploration of the critically important issues presented by this Petition.

The Act, and the Secretary's regulations, ${ }^{29}$ require safety standards to be based exclusively on the record. Section ro5(a)(I) of the Act requires the Secretary to file with the court, if judicial review is sought of an order establishing standards, "the record of the proceedings on which the Secretary based his order ...."

The Order establishing the Initial Standards, including No. 20r, does not discuss the record, does not state what the record contains, and does not state that the Initial Standards are based exclusively upon the record. It is accordingly impossible to determine what the record consists of.

Such deficiencies in the record and Order are understandable in view of the limited time available to promulgate the Initial Standards, and are of no consequence for any standard as to which no major factual or legal issue is raised. But such deficiencies may well be serious in resolving the issues now raised under Initial Standard No. 20x. Before this Petition is rejected in whole or in part upon the basis of any "oral comments" or other matter not contained in the docket file, the substance of these items should be made part of the record and all parties should be given a fair opportunity to reply.

Thus, fearing the chaos of an informal proceeding under section 4, industry attempted to steer the procedure towards the formalities of sections 7 and 8 of the Administrative Procedure Act with its protection of a formal record. The result was a hybrid, part way between two extremes. While the hearing ordered was to be held under section 4, because of the safety act's and the regulations' requirement of a record the presiding officer stated that he would act only on the record developed in the hearing before him. Just what constituted the "record" for Standard 20r was never fully resolved. The Bureau's "proof" offered "on the record" deteriorated to bibliographies and general references rather than comprising affidavit testimony.

By order dated March 29, I967, the Federal Highway Administrator, Lowell K.

${ }^{20}$ [Author's footnote.] "The order [issuing initial motor vehicle safety standards] will be based exclusively on the record." 31 Fed. Reg. I3 328 (I966). But see the current regulations, 23 C.F.R. $\$ 216.27$ (1968), which state: "Any rule issued in a case in which an informal hearing is held is not necessarily based exclusively on the record." 
Bridwell, consolidated the petitions of the various vehicle manufacturers and ordered a hearing before a hearing examiner. On April 7,1967 , the Administrator issued procedural rules to govern the conduct of the hearing and named Mr. Russell A. Potter as the presiding officer. The procedural rules called for the filing of brief statements of position, the holding of a prehearing conference, the filing of written direct and rebuttal testimony, cross-examination on the evidence thus adduced, and the filing of briefs and recommended findings of fact. Reply briefs were not to be permitted. The presiding officer was then to submit his recommended findings, to be followed by written exceptions by the parties. The Administrator was then to decide the fate of Standard 20I "on the basis of information produced in this proceeding, or produced prior to the issuance of Standard No. 20r, and other relevant information."

Following the prehearing conference held on May 4, 1967, the presiding officer issued his report, further refining the issues and laying the groundwork for the presentation of evidence. Noting that the Bureau had agreed that the AMA's statement of the issues was acceptable, the presiding officer adopted this formulation as the issues to be resolved in the proceeding. The AMA had posed the questions concerning Standard $20 \mathrm{r}$ as whether:

(I) It is a minimum standard for motor vehicle performance which is practicable, which protects the public against unreasonable risk of death or injury to persons in the event accidents occur, and which provides objective criteria;

(2) It is practicable, meets the need for motor vehicle safety, and is stated in objective terms;

(3) Relevant available motor vehicle safety data have been considered in issuing it and support it;

(4) It is reasonable, practicable and appropriate for the particular type of motor vehicle for which it is prescribed;

(5) It is based upon existing safety standards; and

(6) It is reasonable or practicable for manufacturers to make the necessary changes in their 1968 model passenger cars so that all passenger cars conform to Standard $20 x$ by January $\mathrm{r}$, I968, or any date thereafter.

With regard to the burden of proof in the proceeding, a difference of opinion arose. The presiding officer indicated the positions of the parties and his own position in his report of the prehearing conference, as follows:

It was agreed that petitioners would proceed first in the presentation of evidence; it was not agreed as to who carried the burden of proof. Petitioners contended that the bureau was the proponent of a rule, and under section 7 of the Administrative Procedure Act, required to carry the burden of proof in establishing the validity of the rule, Standard 2or. The bureau, on the other hand, contended that the burden of proof was upon petitioners, since they were seeking to obtain an order rescinding or amending an existing and effective rule. The presiding officer stated that if the point were involved in resolving any issue, he would consider the burden to be upon the petitioners. 
In further defining the nature and scope of the proceeding, the presiding officer's report stated as follows:

In response to an AMA motion the presiding officer stated that the same rules and practices would be followed in receiving evidence as would be normally followed in any administrative proceeding conducted under sections 7 and 8 of the Administrative Procedure Act. Further, that the findings of the presiding officer would be based exclusively upon the evidence received in this proceeding.

The procedural lines were thus drawn for the taking of evidence about to begin.

\section{B. The Evidence}

\section{r. Phase I-Written Proofs}

The written proofs were filed as scheduled: direct "testimony" (affidavits) on May I2 and rebuttal "testimony" (affidavits) on May 19. No purpose would be served here by reviewing the mass of technicalities contained therein.

\section{Phase 2-Oral Testimony: Warren, Michigan, May 22-23, 1967}

It was here that the turning point was reached. Industry's proof, especially the demonstrative evidence, proved decisive with the presiding officer. The demonstrative evidence was introduced on behalf of the AMA and the four AMA member companies, who were also parties to the proceeding (American Motors, Chrysler, Ford, and General Motors). In accordance with provisions of the Administrator's order aimed at avoiding duplicate submissions of evidence by the parties, the four manufacturers consulted as to the subject matter of the demonstrative evidence and arranged for it to be submitted and explained by one of the companies, General Motors. The other three companies subsequently adopted it in their offers of proof.

A vast quantity of demonstrative evidence had been prepared to prove the impracticability of Standard 20r. Taking 20r literally, mock-ups of automobiles and numerous components thereof had been built as "living proof" of the impossibility of complying with the standard if applied as written. Window crank levers rounded so as not to penetrate the human body in the so-called "second collision" were required by the standard to be so large that the human hand could not grasp them to make them perform their primary function of cranking down or up the windows. (See Figure $\mathrm{I}^{30}$ ) Windshield support posts padded to protect human

\footnotetext{
on " $Q$. What is it you have in your hand, Mr. Klove?

"A. Exhibit IrA. [See Figure $x$. ]

"Q. What is $I I A$, the left part thereof?

"A. This is a model illustrating typical window regulator handles as planned for Ig68. ...

"Q. What is shown on the right?

"A. On the right is shown the handle configurations that would be necessary to meet the requirements of $20 \mathrm{r}$.

"The requirement of $3.3(\mathrm{a})(4)$, that it detach at a load of 90 pounds, is one we could
} 
beings upon impact were required to be so fat as to obscure necessary driving vision. (See Figure ${ }^{3 .}{ }^{31}$ ) The ninety-fifth percentile male manikin and fifth percentile female manikin called for by Standard $20 r$ were not available in actual dummies, ${ }^{32}$ and what dummies did exist could not be maneuvered inside of the automobile for measurement, as was visually demonstrated.

It was an impressive display. Wave upon wave of demonstrative evidence, including both physical demonstrations and exhibits, graphically illustrated the

not comply with since this handle is used to drive the window up and down, and oftentimes is used to pull the door closed. We would not want it broken off in normal usage. Therefore, our only alternative is $3.3(\mathrm{a})(3)$, which specifies first of all that the handle provide and include an area of one square inch from any direction of impact. I have here a half of a six and a half inch diameter ball. When we place it against the door and against the handle, there is a point of tangency, and at that point it must have one square inch area. "Since the knob rotates, it can present any of its surface to that, and therefore for all positions of contact or all positions of the handle it becomes a 2.66 inch diameter sphere. Since this handle must be designed so that it clears the surface of the door, to prevent it from tearing up the surface of the door itself, it results in a dimension larger than one inch from here to the bottom surface of the hard part of the handle. Therefore, it would not be able to comply with the remaining part of $3.3(\mathrm{a})(3)$, that which would require that it deflect to within one inch of the panel surface."

FHA-I, Record at I17-rg.

31 "Q. What is shown by Exhibit $\mathrm{x} 6-\mathrm{A}, \mathrm{Mr}$. Klove? [See Figure 2.]

"A. There is shown the I968 windshield pillar construction and a construction that would be required to meet the Standard $20 x$. ....

"A. Specifically, the requirements of $3.3(2)$, we find that the only way we could qualify or comply" are with the impact deceleration performance requirements, that is, $3.3(a)(1)$.

"Q. Why is that? Would you demonstrate?

"A. First of all, 3.3(a)(2), which would allow us to comply if it were shielded, is one that we could not meet because it is not shielded, and could not properly be shielded. Secondly, the requirements of $3.3(\mathrm{a})(3)$, which would measure its protrusion with reference to panel surface, we cannot comply because there is no panel surface to measure it with reference to. Finally, the reference to $3.3(\mathrm{a})(4)$ the detach at 90 pounds, that could not be applied at this part because it gives a body structure which supports the roof of the vchicle.

"Q. You wouldn't want that to detach under 90 pounds load?

....

"A. We must apply $3.3(\mathrm{a})(\mathrm{r})$, which is the 80 G's deceleration. As I previously cxplained, that would require the addition of crushable space, and from our experience we have estimated that this might be accomplished with an additional two inches of volume between the structural member of the panel and its hard structure. In other words, two inches of crushable space is required."

FHA-I, Record at I32-34.

32 " $Q$. There is a reference to a 95 percentile adult male manikin. Do you have such a device?

"A. Not as referenced in the intent of this standard.

"Q. Is there one available that you know of?

"A. We have two manikins, not 95 , this percentile. We have a crash dummy, 95 percentile Alderson crash dummy."

FHA-r, Record at 36 .

"Mr. O'Mahoney: Is the $H$ point of that dummy, does it conform to Standard 20I?'

"The WrTness: I don't know what the $H$ point of Standard 2or is.

"Mr. O'Mahoney: Do you know what the standard of SAE-J826 is?

"THE WITNESS: Yes.

"Mr. O'MAHONEY: Is that the $H$ point required under Standard 2or?

"THE WITNess: You cannot tell specifically."

FHA-I, Record at 40 . 
impracticability of Standard 20r. The Bureau's chief counsel, Mr. O'Mahoney, objected to the industry's evidence on several grounds. First, he argued that the demonstrations indicated only what industry chose to make of the standards and not what a good faith effort at compliance would have produced. He also claimed surprise and objected that industry had offered a "side-show demonstration that was not done in good faith" and had tried "to make idiots of the federal government." In response to the suggestion that industry's proof was "violative of the spirit of this proceeding" and not relevant to the issues, the presiding officer stated. as follows: $:^{33}$

I have gone through all the direct. I have looked at all the automobiles. And I have tried to familiarize myself with this record as much as I have been able to up to this point. I must confess that seeing the three-dimensional representation of the various components that are involved has been very informative. I think we all ought to see it and appreciate it if we are going to insist on these standards being enforced.

I think that the fact that is involved is the practicability of the standards. And that is the reason for this testimony now, and the reason for the demonstrative evidence that is being displayed.

Industry had no choice but to assume that the Bureau would interpret the standards as written, or strictly against the regulated industry, in which event the models and other demonstrative evidence were quite germane. ${ }^{33 a}$ The act's penalties for noncompliance are such that a manufacturer who chooses to guess at the correct interpretation and guesses wrong may be seriously jeopardized. In any event, overemphasis to make one's point is good trial strategy. Moreover, the presiding officer, who was, preliminarily at least, both judge and jury, was not technically trained, and the purpose of the demonstrative evidence was to inform him of the insuperable difficulties involved in attempting to give effect to the complex technological specifications included in Standard 201.

\section{Phase 3-Cross-Examination: Washington, D.C., May 24-25, 1967}

After the two days of demonstrative evidence, with direct examination and cross-examination to explain its significance and relate it to the written direct and written rebuttal testimony previously submitted, of which it was explanatory, the hearing shifted back to Washington for oral cross-examination on all the written direct and rebuttal testimony. Bureau counsel was to cross-examine industry's

\footnotetext{
${ }^{83} \mathrm{FHA}-\mathrm{I}$, Record at 140 .

ssa The appropriateness of industry's approach was confirmed by the testimony of Soichi Kawazoe, representing the Japan Automobile Manufacturers Association:

"It so happened that in looking over my statement, I have the same pictures, and I can assure you, sir, that this was strictly done in Japan by our engineers according to their interpretation of the standard.

"I particularly want to say, especially, I had a big argument with Tokyo about showing this crazy-looking screw head."

ld. at 494 .
} 
witnesses, following which industry was to cross-examine the Bureau's witnesses. The Board's cross-examination of the witnesses of the twenty-seven petitioners took two days. While it covered old ground, it did not produce any substantial changes.

During the second hearing in Washington, rumors abounded that an agreement might be reached whereby industry would forgo its right to cross-examine the Bureau's witnesses, with the possible humiliation to government that might bring, in exchange for a concession by the Bureau that Standard 20r had to be, and would be, modified. At the conclusion of the Bureau's cross-examination of industry's witnesses, that rumor became fact. With the AMA counsel's waiver of his right to cross-examine, the hearing came to an end.

The following morning, industry leaders and counsel were summoned to the presence of the Federal Highway Administrator to hear a statement, from which the followed passages are excerpts: $:^{34}$

I think that it would be less than realistic on our part for us to take any attitude other than recognizing that at least some modification has to be made in standard 20r. . . . In the final analysis, the public interest will best be served if we can adopt a standard for the interior impact area as strong as possible and still applicable for the 1968 models.

... So what I would like to propose to you today is that we can short-circuit this time problem to the extent that we can by starting work on those modifications that are necessary even prior to the completion of the Hearing Examiner's report.... To the extent that we disagree, it would be my opinion that the Hearing Examiner's findings of fact... would give us a very good indication of how to resolve any elements on which we are not in agreement....

There has been in the Congress some expression of concern over the extent to which the Bureau has been communicating with the industry or communications between the Bureau and the industry and the extent to which there has been a meaningful dialogue. It is my opinion that this is not as good as it should be by any stretch of the imagination; and, as a result of that, last week I wrote to each of the presidents of the primary auto manufacturing companies in the United States asking them ... to meet with me to work out some kind of an organized and systematic liaison system so that we can develop and maintain good communication with the industry.

The concessions thus made and the expression of an apparent willingness to confer at length and on a continuous basis concerning the substance of Standard 201 and future regulation represented important developments. Industry was finally to have its chance to meet with government representatives on an informal, face-to-face, nonadversary basis.

\section{Aftermath}

The administrative procedure then rolled on its regular way, leading to the proposed findings of fact of the presiding officer, even while the Bureau's and

\footnotetext{
${ }^{84}$ FHA-r, Conference Transcript 2-10 (May 26, I967).
} 
industry's technical advisers were meeting to attempt to devise mutually satisfactory modifications of Standard 20r. All this was aftermath. The decisive battle had been won by industry. Standard 20I had fallen.

The Bureau's brief in support of its own proposed findings of fact made numerous concessions to industry's position. It recognized the measurement problems and conceded the utility of the so-called "lollipop" measurement device. It noted that industry's witnesses had "pointed out a number of genuine problems of definition and measurement" and undertook that it would not "utilize interpretations to create an undue hardship on manufacturers during the difficult transition from present dangerous interiors to readily achievable changes that increase occupant protection."

On the subject of leadtime, the Bureau admitted that "many manufacturers" claims of leadtime hardship are undoubtedly legitimate" but contended that "at some point arguments on leadtime change from a legitimate problem of industrial engineering to covert attempts to freeze design to the economic advantage of the manufacturer, but to the detriment of safety objectives." Recognizing the divisibility of the leadtime question, the Bureau undertook that "through informal negotiation and meetings with industry, the Bureau will resolve any clear-cut cases of hardship due to inadequate leadtime."

The Bureau appeared to believe that this concession and agreement to negotiate justified a request that the presiding officer "reserve findings with regard to leadtime and related problems." The AMA, barred from filing a reply brief, nevertheless addressed a letter to the presiding examiner calling attention to the inappropriateness of this request. The letter noted the Administrator's statement at the May 26 meeting to the effect that the presiding officer's report and findings "would be relied upon to help resolve various disagreements."35 As it turned out, the presiding officer's proposed findings of fact, issued on June 22, included the following findings:

I. That II months is not a reasonable period of time in which to require compliance with Standard 20I;

2. That the interior of the car is designed during the first planning and engineering phase, and that pertinent regulatory standards should be available to the manufacturer at that time; and

3. That it is unreasonable to require all components and parts of an automobile interior to comply with Standard 2or within a specified time limit, and not make allowances for the varying degrees of difficulty entailed in their redesign and production.

The presiding officer's other findings of fact were almost all similarly favorable to industry's positions. For example, he found that Standard 201 was not stated in clear objective terms and that the standard was "not limited to performance standards and to requirements that are practicable."

\footnotetext{
${ }^{35}$ Letter to the Presiding Officer from Wilmer, Cutler \& Pickering, Counsel for the AMA (June 15 , 1967).
} 
The Bureau's response to the presiding officer's report was a brief raising numerous important legal and practical questions. While the particular issues concerning Standard 20r were rapidly being worked out informally by the Bureau staff and industry representatives, the Bureau appeared anxious to keep the record clear:

There are many erroneous concepts and mistakes of facts and law contained in the report, [and] we do not want to accede to erroneous assumptions of law madc by the report, nor to establish a precedent for any rulemaking proceedings the Secretary of Transportation may wish to hold on future Federal Motor Vehicle Safety Standards.

Because of the importance of the questions raised and the fact that the issues were not ultimately resolved in the proceedings, it is best to let the Bureau's brief speak for itself on each issue. Accordingly, the following excerpts are provided.

The brief objected that "the report considered the proceeding to be adjudicatory and followed the quasi-judicial requirements of Sections 7 and 8 of the Administrative Procedure Act":

It is a basic administrative law that it is only when a statute requires formal rulemaking procedures be conducted does Sections 7 and 8 of the Administrative Procedure Act apply. If the statute does not specifically require a formal hearing then agencies usually follow the Section 4 informal rulemaking procedure. . . . In rulemaking, the method of trial has no place except when specific facts are at issue, and even then it should seldom be used when the disputed facts are legislative.'

The administrator, in his order of April 21, 1967 , specifically 'ordered that a rulemaking proceeding pursuant to [Section 4 of the Administrative Procedure Act] be conducted.' The proceeding ordered was above and beyond what was required by law. To make findings of fact in a rulemaking proceeding on principles of evidence that relate to adjudicatory hearings is unrealistic, unworkable and impracticable. ... In this case the proceeding was ordered at the discretion of the Administrator to develop the facts and allow the parties to present arguments. The Standard should have enjoyed a presumption of regularity; instead the report consistently balanced the evidence and found that the weight of evidence was with the petitioners.

The courts have upheld the view that the evidence to sustain a rule is far different from that required to sustain an adjudication.... The report failed to consider the rulemaking nature of the proceeding and applied a standard more appropriate to an adjudicatory proceeding.

This failure, based on the erroneous legal reasoning of the report when combined with the presiding officer's misunderstanding of his function makes the report of little or no utility in achieving the objective of the Administrator's hearing order of April 2x, x967. That order clearly stated "Standard No. 20r will remain in effect, be amended, revised, or revoked, by the Administrator on the basis of information produced at this proceeding, or produced prior to the issuance of Standard No. 20r, and other relevant information."

The presiding officer's complete and puzzling failure to grasp this rather simple instruction is documented by the statement at page 4 of the report that 
"additionally, it should be understood that this proceeding has not been directed toward the development of an evidentiary record for amendment of the existing regulations."

Bureau Counsel recognized this misunderstanding on the part of the presiding officer early in the proceedings and made frequent, but obviously unsuccessful attempts to turn the proceeding in the directions of constructive rule making and away from the adversary character to which it was allowed to descend. . . .

Next, the Bureau's brief objected that "the report indicates portions of the standard are invalid because they are not minimum standards":

The report seems to say that if the Bureau goes beyond the minimum the standard is invalid. This construction is wholly unacceptable. The converse is true. The Bureau must write standards that are at least up to a minimum which will protect the public. This means the standard must meet and exceed "minimum requirements," or it has not met the obligation imposed on the Bureau by Congress.

The Bureau's brief then contested the report's implication that "because the standard exceeds existing federal standards it is invalid":

The report finds that Standard 201 exceeds the existing Federal safety standards. With this we find no argument with, but so what? However, the Congress said the initial standards must be based on existing standards not limited to existing standards. Therefore, the fact that Standard 201 exceeds existing standards has very little to do with anything unless it is found that in exceeding existing standards it is no longer based on them.

Finally, the Bureau noted the extraordinarily difficulty involved in drafting regulations that would be free of ambiguity, objecting to the report's allegedly undue stress on exactness of requirements, which, it was claimed, "would make impossible promulgating valid regulations."

The Bureau's experience has been that if the manufacturers were left to their own devices and given all the time they needed they could not produce a standard that would be totally free from ambiguity. Indeed, several sections of Standard 20I which were under industry attack were adopted at the specific request of industry through the Automobile Manufacturers Association.

The report indicates that any ambiguity regardless of degree makes the standard invalid. The precision which the report requires of the standard is recognized by the industry itself to be an impossibility. . . . We do not want the record to indicate that the precision which the report would require is a prerequisite to the validity of any future standard the Secretary may seek to enforce.

Finally, we are at a loss to understand the report's lack of recognition of Bureau's compromise on many portions of the Standards. . . . Bureau recognized that many portions of the standard were unworkable. It said so in its brief and expected that this would, in effect, act as a stipulation. However, the report merely states that the Bureau's suggestions are helpful. . . .

The report, like the regulations themselves, has attempted to deal with a difficult 
complex problem under a difficult time limitation and in an atmosphere charged with emotion.

With the filing of the presiding officer's report and the responsive briefs, the formal proceedings were completed. There continued, however, the informal discussions between industry and the Bureau as to just what Standard 20r, for use in rg68 models (by now only three months away), should contain. Obviously, the realities of leadtime were forcing Standard 20I's requirements closer and closer to what industry had suggested on the basis of existing GSA requirements, most of which were already being prepared for in 1968 production. On June 8 and 9, technical representatives of both industry and the Bureau met in an effort to resolve their differences and draft a workable amendment to Standard 20r. On June 22, the AMA submitted to the Bureau still another draft of the standard, which was claimed to represent "the highest levels of performance for a binding minimum standard that we believe can be physically achieved in all the U.S. I968 model passenger cars about to go into mass production." Further meetings were held on July 6 and 7, and on August II, I967, the new Standard 201 was issued. ${ }^{36}$

The new standard was more workable, though perhaps somewhat less stringent than the original standard in five major respects: ( $I$ ) it substituted known, workable, standardized engineering requirements and testing procedures for vague, unknown, unworkable ones-by changing needed definitions and by changing stated test procedures; (2) it reduced the severity of the impact requirements from " $80 \mathrm{~g}$ for 1.0 millisecond or more" to "8og continuously for more than 3 milliseconds"thus allowing for manufacturing practicability and perhaps even greater safety at higher speeds; (3) it eliminated altogether such troublesome (to define and test) areas of doubtful safety value as protrusions, knee and leg impact areas, console assemblies, jumper seats, etc.; (4) it removed perplexing, unworkable ambiguities in the definitions and testing procedure sections; and (5) by accomplishing the above, it rendered the leadtime problem for this initial standard less acute. The Administrator stated as follows in issuing the revised standard: ${ }^{37}$

After review of the evidence presented at the hearings ordered by the Federal Highway Administration, the report of the presiding officer, and the Bureau's analysis of the engineering meetings with the industry, I have determined that Standard 20r issued January 3I, I967, should be superseded by a new Standard that specifies initial requirements to afford impact protection for occupants and that certain related definitions should be amended accordingly.

\section{Epilogue}

In October I967, the Administrator issued an Advance Notice of Proposed Rule Making to amend the standards for 1969 , 1970, and I971 models and invited com-

\footnotetext{
${ }^{30} 32$ Fed. Reg. 1 I 776 ( 1967 ), now 23 C.F.R. \$255.2I (I968).

${ }^{37} 32$ Fed. Reg. Ir776 (1967).
} 
ments thereon by specific dates in November and December I967 and February 1968..$^{33}$ This time the Bureau scheduled a conference with industry to work out problems on a discussion basis. Thus the machinery for formulating future standards for future models was placed into motion. Presumably the 1967 battle over Initial Standard 201 had set the pattern by forcing the Bureau and industry into closer cooperation so that further resort to reconsideration petition hearings or judicial review would be less likely; instead, primary reliance would be on use of informal conferences similar to those repeatedly requested by industry and finally initiated by the Administrator on May 26, 1967 . In view of the importance of the automobile industry to the economy and of personal safety to the public, perhaps the public interest will best be served by continuing to follow this route in the future.

Following its experience with Standard 20r, the Bureau has proceeded to organize itself for the job of continuing regulation in the years ahead. Its approach appears likely to be less influenced by political developments and to be more in keeping with technological and economic realities. One instance of the Bureau's efforts to grapple realistically with the economics of automobile safety is the creation in June I 968 of an Office of Leadtime and Cost Analysis. Concurrently the Bureau released two extensive research studies on the subject of leadtime, which were prepared for it by the accounting firm of Arthur Young \& $\mathrm{Co}$. and by the firm of Booz, Allen \& Hamilton, management consultants. ${ }^{39}$ These studies will provide needed under-

\footnotetext{
${ }^{38} 32$ Fed. Reg. ${ }^{3278}$ ( 1967 ).

30 Arthur Young \& Co., Automotrve Industry Enginefring Study (1968); Booz, Allen \& Hamilton, Automotive Industry Engineerning Study (I968). See Automotive News, June 24, I968, from which the following summary has been paraphrased. The Arthur Young study stresses the need for government's appreciation of the possibility of excessive economic effects and the establishment of priorities in the promulgation of new safety regulations. Among the factors to be considered should be $(a)$ the exact type of cost perturbed by the standard, $(b)$ the timing of the introduction of change within the three to four year production cycle, $(c)$ the number of cars affected, with consideration of both unit and aggregate costs, $(d)$ potential for cost recovery, and $(e)$ the aggregate cost as a part of the total company investment.
}

The Young study divides the production cycle into eight stages: ( $x$ ) product conceptualization (about 48 months before production startup), (2) concept feasibility and development (ending about 36 to 42 months before production), (3) body and structural development (from 36 to 24 months prior to production), (4) management's program approval (about 22 months before production), (5) a year of detailed engineering ending about 12 months before production, (6) tooling construction and parts procurement ending four to five months before production, ( 7 ) a two to three month pilot assembly during the last six months before production, and (8) production changeover. The study suggests that the Bureau should examine this cycle in detail and set up a pragmatic model to be coordinated with its data center and Office of Leadtime and Cost Analysis. The first three stages of the cycle are measured in millions and tens of millions of dollars, but from here on out the multiline makers commit several hundred millions of dollars. It is still possible to change, but it becomes much harder and costlier. Thus, arbitrary introduction of standards might force some companies out of business. To avoid this, the Bureau should consider the cost-benefit ratio of each regulation and the different methods of introduction such as (a) optional introduction with a deadline, (b) graded or classified introduction, $(c)$ rolling introduction at the next logical change of the involved component, (d) subsidized introduction by tax relief, research grants, etc., and (e) negotiation with makers over the introduction.

The Booz, Allen \& Hamilton study sets out a number of working hypotheses for the Bureau: The 
standing to assist the Bureau in the promulgation of regulations that are both reasonable and practicable. They will also serve to emphasize the cost of particular safety devices and the cost of their introduction into the production process. If the Bureau sees fit to adopt the recommendations of the reports or to adopt other procedures consistent with the approaches and considerations outlined therein, the outlook for intelligent, economically sound regulation in the public interest would appear to be good.

\section{Critique}

Whether generalized rules or observations can be drawn from this rather unique experience is difficult to say. Perhaps we would do best to approach the task with the background provided by Professor David F. Cavers' excellent article entitled "Administering That Ounce of Prevention: New Drugs and Nuclear Reactors." This article reviews in some detail the somewhat similar experiences of the Food and Drug Administration (FDA) and the Atomic Energy Commission (AEC) in regulating other industries in which sensitive safety problems are encountered. Professor Cavers' purpose is to consider methods by which the law's processes have been or can be adapted to answering difficult scientific and technological questions. Admittedly, the licensing of new drugs or nuclear reactor construction is distinguishable in many respects from the largely legislative process by which the National Highway Safety Bureau formulates safety standards to which auto manufacturers must adhere. Nevertheless, the use of the administrative process, and particularly the method of adversary presentation of evidence, as a means of establishing the facts concerning the relationships among technology, economics, and public safety is one of the great challenges that government and the legal system now confront. For this reason, it is useful to attempt to draw some conclusions from the experience just recounted.

One point that Cavers stresses is the lack of an effective appeal available to industry in the areas that he investigates. In both drug licensing and reactor safety review, the agency staff is able to effectuate its will without substantial risk that the applicant will appeal to the highest administrative authority or the courts. No

first is that there can be improvements in the standards practices. The Burcau should issue (a) notices of proposed rulemaking about 39 months before production, $(b)$ draft standards 24 months before production, and $(c)$ issue final standards 18 months before production. The need is to recognize that there are "critical stages" for the body shell as well as for components and to be aware of how their cycles interact. Reducing these safety regulation' leadtimes may raise costs by as much as one-third. Second, future changes in the production cycle will probably be evolutionary. Third, there will be more standards, and they will have greater impact on vehicle design. Fourth, the Bureau's job in introducing standards will become more complex. Fifth, the Bureau should use the basic forces within the industry. Included are the drive to attain an acceptable return for the stockholders, the wants and demands of the vehicle ownership group, and the continual struggle to equal or exceed competitors. Sixth, primary stress should be placed on creating customer demand for safety improvements.

${ }^{10}$ Part I, 68 W. VA. L. Rev. $\operatorname{rog}$ (1966); Part II, id. at 233 [hereinafter cited as Cavers]. 
parallel seems to exist in the situation we have been reviewing, since industry was forced to take a stand at the earliest possible date to resist what it deemed unworkable requirements. Indeed, the automobile industry had no real choice, as the requirements determined no less than whether the industry could produce and sell I968 model passenger cars. On some of the lesser issues, where that imperative was not involved, there were other considerations. First, standards were being imposed on an established industry that had never before been regulated, and the unprecedented character of the occasion created a sort of "territorial imperative" and made a strong stand important. Second, the industry was a giant, possessing vast resources and know-how to finance a battle with a less experienced and undermanned adversary. Third, the industry risked no trade secrets in the public hearing, as may often occur in FDA cases. Industry appears to have established its willingness to resist impositions that are deemed unreasonable, and this willingness should serve to generate a degree of caution and conscientiousness on the part of the Bureau in exercising its authority.

Of course, the merits of the Standard 20r controversy were clearly with industry, and the remedy of a petition for reconsideration will not always be as valuable as it appeared under these circumstances. Cavers notes that the report of a hearing examiner in a new drug case ${ }^{41}$

would be reviewed and a decision reached by the Secretary's delegate, none other than the Commissioner of Food and Drugs. One may predict with some confidence that, unless the applicant can bring significant new testimony to the fore, or can dissipate misunderstanding concerning its product, the Commissioner will reach the same decision after the hearing that he had reached before it, since the latter decision would have been rendered only after a careful appraisal of the applicant's case informally presented.

The Standard 20x proceeding clearly fits Cavers' stated exception for the case where "the applicant can bring significant new testimony to the fore." In a closer case, the Bureau will clearly have presumptions in its favor, and industry's best forum for protecting its legitimate interests probably lies in the continuation of the informal discussions with the Bureau staff that emerged in the aftermath of the Standard 201 proceedings.

While the issues involved in the Standard 20x hearings were of a technical nature, it was possible for the issues to be made clear enough so that the presiding officer, a lawyer without extensive technical background, could understand the problems. In other cases, the issues will be less clear and will require a decision on the merits of conflicting technical arguments and the weight of scientific experimental evidence. In such a case a hearing officer may not be capable of reaching the proper decision. Cavers notes the limitations of the ordinary hearing examiner as follows: ${ }^{42}$

\footnotetext{
1 Cavers, Part I, at 123 .

${ }^{19}$ Id. at $13 \mathrm{I}$.
} 
$\mathrm{He}$ is a lawyer skilled in guiding the course of the hearing as its presiding officer and in ruling on procedural points. However, if he makes findings of his own, they are the findings of a layman. The [Food and Drug] Commissioner, whether layman, scientist or physician, is not materially advanced by them in reaching his own decision.

The problem seems not to be materially different in the case of automobile safety. One method of fact finding and administrative review that has been suggested to meet this problem is the possibility of using a panel of expert advisers to review the results of administrative decision making. This practice has been adopted in atomic energy regulation, ${ }^{43}$ and has been proposed for use by the FDA. Cavers writes, ${ }^{44}$

Before a final decision is reached at the administrative level, [some] critics contend, an applicant ought to be able to present his case to a panel of expert advisers. They may not often decide in his favor, but if and when they do, their decision is likely to be respected by the [FDA] Commissioner. Moreover, the critics argue that the mere power to demand review will assure the applicant a more careful evaluation of its [new drug application].

A problem in implementing any such approach in the area of automobile safety lies in the fact that industry possesses most of the expertise in the field and that other independent experts are rapidly being preempted by their employment by the Bureau. Still, the Administrator's post-hearing suggestion of May 26, rg67, calling for meetings between technical experts from both industry and government to hammer out amendments to Standard 20I, constitutes perhaps the closest thing to the use of a panel of expert advisers that could be accomplished in this field. If the technicians can approach their task in a professional way and avoid undue partisanship and indulgence in advocacy, the system should provide a mechanism for accomplishing safety without undue sacrifice of other values. While the process is still to be regarded as experimental, it holds immense promise.

Lest the creation of a panel of experts appear as a panacea to the problem of finding technical facts and weighing difficult technical and scientific evidence, Cavers' recitation of the dangers that might accompany such a system should be noted (the quoted language is that of Dean William C. Warren) $:^{45}$

[T] he administrator who is advised "by a panel of distinguished experts" [is] "likely to adopt the recommendations as his decision, without the soul-searching critical analysis to which he would subject the same recommendation from his own official staff...." Not only is the administrator shielded from congressional criticism if he relies on such a panel's advice, but, Dean Warren points out, criticism would be doubled if he disregarded the panel's advice and events later

\footnotetext{
${ }^{4}$ See Murphy, Atomic Safety and Licensing Boards: An Experiment in Administrative Decision Making on Safety Questions, in this symposium, p. 566 .

" Cavers, Part I, at 125 .

${ }^{4}$ Cavers, Part II, at 258-59, quoting Warren, Congressional Investigations: Some Observations, 21 Food Drug Cosm. L.J. 40, 45 (1966).
} 
proved him wrong. Tempted to take the safer course, he "abdicates his official function."

Cavers then notes the possibility that the best of both systems-the public hearing before a hearing examiner and the hearing before an ad hoc committee of expert advisers-might be obtainable. Addressing himself to the FDA's problems, he argues: ${ }^{40}$

I submit that, to handle the hard case where neither the FDA nor the applicant is ready to back down, a public hearing is preferable to a mandatory ad hoc advisory committee. However, in providing for such a hearing, the FDA could well take a leaf out of the AEC's book. Let a hearing examiner or other lawyer be the presiding officer of a hearing board to which two or four experts would be appointed, chosen from a panel for the relevance of their expertise. An initial decision by such a board would not, of course, be binding on the Commissioner, but the record before it would provide a public basis for appraising the wisdom of his decision or the lack thereof.

These thoughts would appear to be of possible value in formulating a system for devising automobile safety standards. Nevertheless, the limitations are real, and more promising long-run results must be expected not from adversary review proceedings, which will be extraordinary and reflective of a breakdown in agencyindustry understanding, but from the day to day turning of regulatory wheels in a cooperative atmosphere characterized by continuing contact and consensus.

The possible dangers of adopting informal negotiation as the primary means of formulating future safety standards are several. Perhaps the primary cause for concern is the possibility that the Bureau will become, as other agencies are alleged to have done, the servants of the regulated industry. Cavers notes the common charge that agency staffs often come to adopt the regulated industry's viewpoint, or that agency employees tend to curry favor with industry in hopes of obtaining future employment. This concern is well taken, but it does not seem to be a significant danger at present in the auto safety field. Indeed, it is usually thought that the capturing of an agency is a gradual process which begins only after an initial flurry of regulatory zeal. It would appear that we have witnessed the first stage of this process only, and there is no reason as yet to fear an industry take-over. In formulating its initial standards, the Bureau appears to have done its best to regulate in the public interest, but was handicapped by many factors, including lack of technical staff, lack of time, and lack of available expertise. It stood its ground and fought to the very end, and there are reasons for believing that its fight against substantial odds was motivated primarily by a wish not to appear as having capitulated to industry. One great benefit of the proceedings was probably the demonstration that it provided of both industry's credibility and the Bureau's independence, thereby laying the foundations for a meaningful dialogue. What the

\footnotetext{
${ }^{40} 1 d$. at 259 .
} 
passage of time will reveal about the Bureau's ability to maintain its regulatory integrity remains, of course, to be seen.

If, as has been suggested, the future of regulation in this field finds greater stress placed on the process of negotiating the substance of safety regulations in advance of their promulgation, some potential problems certainly must be acknowledged. The overriding problem is the removal of the process of regulation from the public arena to the negotiating table. This shift from the spotlight to the shadows can be expected to concern those who might suspect that the agency has been captured by the industry. If the resulting regulations fail to satisfy the expectations of these interested persons, the results may be attributed to subversion rather than to an honest decision on the merits. Even among those less likely to suspect conspiracy, there is a legitimate concern that decisions be reached with sufficient openness that mistakes and overly generous compromises can be noted and appropriately criticized. The process of negotiating and compromise is discussed by Cavers as follows: ${ }^{47}$

[T] he [agency's] choice will rarely be between intransigence and surrender. The label claim can be modified, but not as much as was first insisted on; the extra reactor study can be undertaken but on a smaller scale; the design altered but less importantly. Compromises like these are inevitable, and probably are very often in the public interest. Unfortunately, if the staff is weak or its morale low, the staff may yield more than the public interest would allow. This risk is one of the main reasons why a need may be felt for an open review of administrative decision-making before the process is completed.

One might expect that this problem could be met most effectively by the Bureau's publishing, with its regulations, the data on which they are based and the reasons for resolving particular questions in a particular way.

The other side of the coin is, of course, that the Bureau may be overly zealous on occasion and may insist on safety devices that are unproven or that cost more than they could conceivably return in the form of added safety. In the case of Standard 201 the problem was the shortness of leadtime and the ambiguity of the standard itself, which problems stemmed mostly from the time pressure placed on the Bureau by political events. There appears to be no great danger that these precise problems will arise again, but the possibility of unwise regulation is always real. While the legislation contains protections for industry from over-regulation, the industry must feel that its best hope for obtaining a full hearing of its views and their factual basis lies in informal dealings with Bureau personnel. Industry should recognize, however, that undue secrecy will not serve its best interests in the long run. In other words, the following conclusions of Professor Cavers should be noted $:^{48}$

[S]ooner or later the public will reject expert judgments on which hang the safety of many people unless at least some of these judgments can be and are validated

\footnotetext{
${ }^{4}$ Id. at 242.

${ }^{18}$ Cavers, Part II, at $26 \mathrm{r}$.
} 
by public processes, however unscientific. One way to provide public validation is resort on occasion to a public hearing before a tribunal manned by knowledgeable people of demonstrated independence, whose conclusions can be rejected by the final decision-makers in the agency only on the basis of reasoned opinions, themselves subject to public appraisal.

If this or some comparable check is not available, if the staff's work is done and reviewed in secret, the agency, its staff and its processes will all risk becoming the object of suspicion, perhaps not from the public at large but from a relatively small but concerned and articulate group of independent experts and laymen. If there is no effective way for these critics to take part in the process of decision or to evaluate the judgments it yields, they will exploit whatever agency errors hindsight has laid bare and turn to political processes. The most available of these are appeals to congressional committees and to the citizenry at large, ranging from indignant letters to the editor to the hair-raising best seller. Secrecy is not likely long to survive these assaults, nor will public and professional confidence in the agency.

Government has undertaken to "administer the ounce of prevention" to minimize traffic accidents and especially the carnage of the so-called "second collision." In doing so, it has had to regulate for the very first time a key industry in the nation's economy. Its legislators attempted compromise in passing the statute itself. Its Administrator, through the rule making procedure with a public hearing followed by a negotiated revision of Initial Standard 20r, achieved that compromise in fact. The first step forward was a cautious step. This was as it should be, especially in view of the critical shortage of leadtime and the infancy of the art of "bio-mechanics" testing.

\section{Conclusion}

No one can quarrel with the senseless tragedy of highway accidents, nor with the thesis that many, if not most, such accidents are caused by driver error rather than by car design or performance. On the other hand, so long as automobiles are operated by human beings, there will be accidents: the driver will have "one for the road" too many, he will be preoccupied and fail to see the stop sign in time, he will skid on ice, slide in the rain, be blinded by the sun by day and the lights of oncoming automobiles at night. This being so, no one can quarrel with the thesis that the so-called "second collision" is of great importance. We must do all that we reasonably can to reduce the number of auto accidents, but, since we can never eliminate accidents altogether, we must also do all that we reasonably can to minimize the damaging effects of such accidents as do occur.

Industry itself had long recognized the safety problem and had tried to meet it by adding safety features to passenger cars as determined by market acceptance. (The public's stubborn refusal to utilize seat belts persists to this day. ${ }^{49}$ ) Thus it

${ }^{10}$ Cleveland newspapers reported 2I fatalities from auto accidents over Memorial Day Weekend in Mfay 1968. All cars had seat belts. None were fastened. 
would seem that safety will always be a series of compromises between providing protection on the one hand and, on the other hand, not creating undue problems of cost and customer acceptance. It would seem the most that government regulation can do is to shift the point of compromise.

Approaching the problem with some attempt at objectivity, one must concede at the outset the hopeless inadequacy of the Initial Standard 201 of January 31, 1967. The reasons for this seem threefold:

First, time-or more accurately the lack thereof. Congress, in a political derby, had demanded too much too soon from too new and too understaffed an agency. A mandate from Congress on September 9, r 966 , for the promulgation of standards by January $3 \mathrm{r}$, 1967, on a very complex subject by an agency which did not exist before September 9, rg66, and did not receive its first funds until near the end of September 1966, was asking too much. To achieve any standards-let alone standards without flaws-under such conditions was a Herculean task.

Second, technical expertise-or more accurately the lack thereof. Because there is so little factual knowledge in this field of inquiry, especially "bio-mechanics," experts were hard to come by. Without such expertise, mistakes in Initial Standard 20I were to be expected.

Third, the lack at that time of meaningful communication between industry and agency-a deficiency apparently cured by the experience herein set forth. Because of the time pressures imposed by Congress and the birth pangs involved in establishing a wholly new activity, the Bureau had neither the time nor the people necessary to fully digest the comments submitted by industry, and the Bureau struck out on its own. That its first efforts were far from perfect is therefore understandable.

What then of the public interest? In this initial struggle, did it come out the loser in the end? It would not seem so. Safety standards were achieved affecting I968 model private passenger cars. While they were less stringent than some members of the Bureau wanted, they were a first step forward. They were a workable step, a step that industry was able to take, a step that would not cause the industry to stumble economically, which would have hurt the entire economy and hence the public interest. Frankly, insofar as Standard $20 \mathrm{r}$ is concerned, a greater step into the dark unknown of "bio-mechanics" might have been fraught with danger and most unwise. Steps in the dark should be short, cautious ones. There are years ahead, and new models each year. Other steps remain to be taken. As the growing expertise of "bio-mechanics" begins to light the way, the steps can become longer and surer. "A journey of a thousand miles begins with a single step." That step has been taken.

In spite of some adversary bitterness, the administrative process has worked. Credit would seem to belong to the willingness to compromise constantly displayed by the leaders of both sides-which, one supposes, is politics at its best-and also to 
the Presiding Officer, who charted a steady course through emotionally charged seas and interpreted correctly a mass of engineering technicalities.

Fortunately for the public interest, the necessary compromises were forthcoming in time to save the day. It is hoped that the format thus achieved-of formulating regulations through communication and mutual compromise rather than through litigation-will serve as a guide for the formulation of regulations governing the production of succeeding models in the years to come. If so, this initial litigation, unavoidable in the circumstances, will have been constructive. 